\title{
Synthesis and magnetic study of Co-Al substituted calcium hexaferrite
}

\author{
K G REWATKAR*, N M PATIL ${ }^{\dagger}$ and S R GAWALI \\ Department of Physics, Dr Ambedkar College, Nagpur 440 010, India \\ ${ }^{\dagger}$ Department of Applied Physics, Nagpur University, Nagpur 440 001, India \\ ${ }^{*}$ Department of Physics, Dr Ambedkar College, Chandrapur 442 401, India
}

MS received 25 April 2005

\begin{abstract}
A series of calcium substituted polycrystalline ferrite ceramics with magnetoplumbite structures were synthesized using perfect stoichiometric mixtures of oxides with chemical composition, $\mathrm{CaAl}_{x} \mathrm{Co}_{x} \mathrm{Fe}_{12-2 x} \mathrm{O}_{19}$ $(x=2-5)$, by standard ceramic technique. The variation in the values of $H_{c}$ and $M_{s}$, which depends on the additive content and the temperature, was studied by means of a vibration magnetometer. The strong variation observed in coercivity, saturation magnetization and Curie temperature with chemical composition give rise to the possibility of controlling these properties and hence applying these compounds in the millimeter-microwave range.
\end{abstract}

Keywords. Polycrystalline ferrites; saturation magnetization; Curie temperature; coercivity; magnetoplumbite.

\section{Introduction}

$\mathrm{Ba} / \mathrm{Ca}$-ferrite particles media is considered a promising material for high density magnetic recording (Speliotis 1987) and many attempts have been devoted to improve their magnetic characteristics by substitution of $\mathrm{Fe}^{+3}$ cations with other diamagnetic or paramagnetic cations (Figgis and Nyholm 1958). Although single-domain $\mathrm{Ba} / \mathrm{Ca}$ ferrite particles have an intrinsically large coercivity $H_{\mathrm{c}}$, it is known that substitution with equimolar $\mathrm{Co}^{+3}$ ions may dramatically alter $H_{\mathrm{c}}$ without significantly affecting the magnetism (Kubo et al 1982). Structurally, $M$-type ferrites consist of spinel $(S)$ block interspersed with five distinct lattice sites for the metallic cations (table 1). Each $\mathrm{Fe}^{+3}$ ion sublattice contributes differently to the overall character of the ferrite. In $\mathrm{CaFe}_{12} \mathrm{O}_{19}(\mathrm{CaM})$ the usual quasilinear temperature dependence of the saturation magnetization, $M_{\mathrm{s}}$, results from a rapid decrease in the contribution from the octahedral $12 \mathrm{~K}$ sublattice. This has been interpreted as indicating that the $12 \mathrm{~K}$ ions interact strongly with the bipyramidal $2 \mathrm{~b}$ sublattice, in addition to the expected super-exchange interaction with the spin down $4 f_{\mathrm{IV}}$ and $4 f_{\mathrm{VI}}$ ions (Albanese 1977). Similarly the characteristic uniaxial anisotropy of CaM has been attributed to the dominating contributions from the single ion anisotropies of the $12 \mathrm{~K}$ and $2 \mathrm{~b}$ sublattices (Asti and Rinaldi 1976). The magnetic behaviour of the compound has been explained in the light of interactions amongst the ions occupying these crystallographic sites. Various comparative magnetic interactions occurring in the lattice due to several site distributions, which in turn decide the

\footnotetext{
*Author for correspondence (kishor_rewatkar@ rediffmail.com)
}

magnetic behaviour. In the present study a series of four compounds with general formula, $\mathrm{CaAl}_{x} \mathrm{Co}_{x} \mathrm{Fe}_{12-2 x} \mathrm{O}_{19}$ with $x=2,3,4$ and 5 are reported.

\section{Experimental}

The synthesis of polycrystalline $\mathrm{CaAl}_{x} \mathrm{Co}_{x} \mathrm{Fe}_{12-2 x} \mathrm{O}_{19}$ $(2<x<5)$ samples were done by high temperature solid state reactions of stoichiometric mixtures of $\mathrm{AR}$ grade $\mathrm{CaO}, \mathrm{Fe}_{2} \mathrm{O}_{3}, \mathrm{Al}_{2} \mathrm{O}_{3}$ and $\mathrm{Co}_{2} \mathrm{O}_{3}$ oxides. The synthesis was divided into two steps: (i) After calcinations at $800^{\circ} \mathrm{C}$ for $2 \mathrm{~h}$ in air. The mixture was grinded and dried, compressed into pellets, and (ii) finally subjected to a thermal treatment at $1200^{\circ} \mathrm{C}$ for $1250 \mathrm{~h}$ with intermediate grinding and were quenched in air. The preparational procedure was similar to that reported earlier (Kulkarni and Prakash 1994; Rewatkar et al 1998). The samples were analysed using an X-ray powder diffractometer with filtered $\mathrm{CuK} \alpha$-radiation with nickel as a filter. The magnetic susceptibility measurements were carried out on Gouy's balance in the temperature range $300-850 \mathrm{~K}$, using mercury-cobaltate-tetrathiocynate $\left[\mathrm{HgCo}(\mathrm{CNS})_{4}\right]$ as calibrant (Lotgering et al 1980). The ferrites doped with high concentration of $\mathrm{Co}^{+3}$ possess high Curie temperature, the additive components were restricted within the interval of $2 \leq x \leq 5$.

The magnetic measurements on polycrystalline samples were carried out by using a vibrating sample magnetometer in the applied field up to 300 Oes at room temperature, which is indicative of substitution of $\mathrm{Fe}^{+3}$ with $\mathrm{Co}^{+3}$ and enhances the intensity of magnetization.

\section{Results and discussion}

Synthesis of polycrystalline samples were verified using 
Phillips X-ray diffractometer and $\mathrm{Cu}-\mathrm{K} \alpha$ radiation with wavelength, $\lambda=1.542 \AA$. The X-ray pattern showed a single crystalline phase without any trace of impurity indexed as hexagonal magnetoplumbite structure (Sharrock 1989). The structural data of compound, $\mathrm{CaAl}_{2} \mathrm{Co}_{2} \mathrm{Fe}_{8} \mathrm{O}_{19}$, is given in table 2. By isomorphism of the $\mathrm{M}$ compounds the space group is presumed to be $D_{6 \text { th }}^{4}$ or $\mathrm{Pb}_{3} / \mathrm{mmc}$ (Kojima 1982). The hexagonal lattice parameters of the compounds were deduced from XRD pattern. The replacement of $\mathrm{Al}^{+3}$ ions has been investigated because of resemblance of the ionic radii. It is seen that the former ions are very easily replaced at any substitution ratio without changing the crystal geometry. The lattice parameters ' $a$ ' and ' $c$ ' increase linearly with substitution of $\mathrm{Fe}^{+3}$ and $\mathrm{Co}^{+3}$ ions in $\mathrm{Ca}$-ferrite.

It is obvious as $\mathrm{Fe}^{+3}$ and $\mathrm{Co}^{+3}$ ions have larger ionic radii $(0.64 \AA, 0.63 \AA)$, respectively than $\mathrm{Al}^{+3}(0.50 \AA)$ and hence ' $a$ ' is predominantly governed by large $\mathrm{Fe}^{+3}$ ions. A perusal of the structure shows that ' $c$ ' is more suscep- tible to stoichiometric changes than ' $a$ '. The lattice parameters and consolidated data on coercivity $\left(H_{\mathrm{c}}\right)$, saturation magnetization $\left(M_{\mathrm{s}}\right)$ and magnetic moment $(\mu)$ are enumerated in table 3 . The magnetic moment, $\mu$, per unit formula of the compounds were in the range of 13.01-16.12 $\mu \mathrm{B} / \mathrm{FU}$, this value is much smaller than $20 \mu \mathrm{B} / \mathrm{FU}$ for $\mathrm{BaFe}_{12} \mathrm{O}_{19}$ ferrite. This indicates that substitution of $\mathrm{Fe}^{+3}$ with $\mathrm{Co}^{+3}$ and $\mathrm{Al}^{+3}$ ions causes a strong decrease of the magnetic moment and occupation of spin up sites by $\mathrm{Al}^{+3}$ ions particularly.

The $12 \mathrm{~K}$ sublattice (spin up) is antiferromagnetically coupled with the $2 \mathrm{~b}$ (spin up) and $2 \mathrm{a}$ as well as the $12 \mathrm{~K}$ intersublattice interactions and have only perturbing effect on the orientation of magnetic moment of $12 \mathrm{~K}$ ions. The neutron diffraction and NMR studies also reveal that $\mathrm{Co}^{+3}$ ions are mainly distributed within $4 f_{\mathrm{IV}}$ and $12 \mathrm{~K}$ sites (Henry et al 1953; Smit and Wijn 1959).

The strong increase in Curie temperature $\left(T_{\mathrm{c}}\right)$, saturation magnetization $\left(M_{\mathrm{s}}\right)$ and coercivity $\left(H_{\mathrm{c}}\right)$ demonstrates that

Table 1. Distribution of the cations and spin orientations for various sublattices of $M$-type hexaferrites.

\begin{tabular}{llccc}
\hline \multirow{2}{*}{ Sublattice } & Coordination & Block & Number of ion & \\
\hline $2 \mathrm{a}$ & Octahedral & $S$ & 1 & Spin orientation \\
$2 \mathrm{~b}$ & Pseudo-tetrahedral & $R$ & 1 & up \\
$4 f_{\mathrm{IV}}$ & Tetrahedral & $S$ & 2 & up \\
$4 f_{\mathrm{VI}}$ & Octahedral & $R$ & 2 & down \\
$12 \mathrm{~K}$ & Octahedral & $R-S$ & 6 & down \\
\hline
\end{tabular}

Table 2. X-ray diffraction data of $\mathrm{CaAl}_{2} \mathrm{Co}_{2} \mathrm{Fe}_{8} \mathrm{O}_{19}$.

\begin{tabular}{|c|c|c|c|}
\hline$d_{\mathrm{obs}}(\AA)$ & $d_{\text {cal }}(\AA)$ & $I / I_{0}$ & $h k l$ \\
\hline $3 \cdot 6154$ & $3 \cdot 6155$ & $6 \cdot 3$ & 104 \\
\hline $3 \cdot 5438$ & $3 \cdot 5441$ & $12 \cdot 2$ & 006 \\
\hline $2 \cdot 8789$ & $2 \cdot 8784$ & $17 \cdot 0$ & 106 \\
\hline $2 \cdot 7964$ & $2 \cdot 7973$ & $30 \cdot 9$ & 110 \\
\hline $2 \cdot 7055$ & $2 \cdot 7053$ & $5 \cdot 1$ & 112 \\
\hline $2 \cdot 5863$ & $2 \cdot 5863$ & 100 & 107 \\
\hline $2 \cdot 6020$ & $2 \cdot 6021$ & $21 \cdot 2$ & 113 \\
\hline $2 \cdot 4754$ & $2 \cdot 4754$ & $84 \cdot 8$ & 114 \\
\hline $2 \cdot 4400$ & $2 \cdot 4499$ & $14 \cdot 7$ & 201 \\
\hline $2 \cdot 3386$ & $2 \cdot 3395$ & $36 \cdot 3$ & 108 \\
\hline $2 \cdot 3206$ & $2 \cdot 3294$ & $13 \cdot 5$ & 203 \\
\hline $2 \cdot 1960$ & $2 \cdot 1959$ & $6 \cdot 5$ & 116 \\
\hline $2 \cdot 1312$ & $2 \cdot 1307$ & $12 \cdot 5$ & 109 \\
\hline $2 \cdot 0223$ & $2 \cdot 0244$ & $37 \cdot 5$ & 206 \\
\hline $1 \cdot 8312$ & $1 \cdot 8314$ & $44 \cdot 4$ & 210 \\
\hline 1.6428 & 1.6439 & $7 \cdot 3$ & 300 \\
\hline 1.5713 & 1.5706 & $8 \cdot 2$ & 304 \\
\hline 1.5333 & 1.5334 & $6 \cdot 2$ & 305 \\
\hline 1.3988 & $1 \cdot 3987$ & $16 \cdot 2$ & 220 \\
\hline $1 \cdot 3723$ & $1 \cdot 3723$ & $15 \cdot 2$ & 223 \\
\hline $1 \cdot 2711$ & $1 \cdot 2711$ & $8 \cdot 3$ & 2015 \\
\hline $1 \cdot 1739$ & $1 \cdot 1739$ & $5 \cdot 5$ & 319 \\
\hline $1 \cdot 1560$ & $1 \cdot 1561$ & $6 \cdot 3$ & 2017 \\
\hline 1.0573 & 1.0573 & $6 \cdot 2$ & 410 \\
\hline
\end{tabular}


Table 3. Data on lattice parameters $a$ and $c, H_{\mathrm{c}}, M_{\mathrm{s}}, \mu$ for $\mathrm{CaAl}_{x} \mathrm{Co}_{x} \mathrm{Fe}_{12-2 x} \mathrm{O}_{19}$.

\begin{tabular}{lccccccc}
\hline S1. no. & $x$ & $a(\AA)$ & $c(\AA)$ & $H_{\mathrm{c}}(\mathrm{Oes})$ & $M_{\mathrm{s}}(\mathrm{emu} / \mathrm{g})$ & $\mu$ & $T_{\mathrm{c}}(\mathrm{K})$ \\
\hline 1 & 2 & $5 \cdot 6950$ & $21 \cdot 2620$ & $115 \cdot 0$ & $10 \cdot 71$ & $13 \cdot 01$ & 634 \\
2 & 3 & 5.7939 & $21 \cdot 8075$ & $168 \cdot 0$ & $26 \cdot 37$ & $14 \cdot 01$ & 725 \\
3 & 4 & $5 \cdot 8074$ & $21 \cdot 8410$ & $198 \cdot 5$ & $39 \cdot 11$ & $15 \cdot 81$ & 798 \\
4 & 5 & $5 \cdot 8185$ & $21 \cdot 8798$ & $215 \cdot 0$ & $51 \cdot 63$ & $16 \cdot 12$ & 823 \\
\hline
\end{tabular}

some inter sublattice exchange interactions are dominant. It can be seen that the spin co-linearity appears mostly in the spin up sublattice, especially the $12 \mathrm{~K}$ sublattice has degree of frustration being in this way strongly affected by increase of $12 \mathrm{~K}-4 f_{\mathrm{IV}}$ interaction. A mean field analysis of the exchange interaction in BaM hexaferrite has been carried out by Isalgue et al (1986). The result shows that the $\mathrm{Fe}(12 \mathrm{~K})$ sublattice making a link among $R$ and $S$ structural block is subjected to very strong competitive exchange interaction. So, when the $\mathrm{Fe}^{+3}$ ions in the $12 \mathrm{~K}$ sublattice are substituted by nonmagnetic ions, weakening of the super exchange interaction between magnetic ions results in a fairly inclined ferromagnetism.

The measurements of $M_{\mathrm{s}}, H_{\mathrm{c}}$ and $\mu$ imply an increase with $\mathrm{Fe}^{+3}$ and $\mathrm{Co}^{+3}$ ion concentration in series, which are indicative of ferromagnetic nature of the compounds. The continuous increase in $H_{\mathrm{c}}$ and $M_{\mathrm{s}}$ with decrease of $\mathrm{Al}_{2} \mathrm{O}_{3}$ contents may be explained by assuming that $\mathrm{Al}^{+3}$ substitution is preferentially performed on the spin up magnetic sublattice, for the composition. Similar phenomenon has also been reported (Stepankova et al 1991) in $\mathrm{SrO}_{(6-x)}$ $\mathrm{Fe}_{2} \mathrm{O}_{3 x} \mathrm{Al}_{2} \mathrm{O}_{3}(0<x<6)$ ferrite system.

\section{References}

Albanese G 1977 J. Physique Colleque C1 38, 85

Asti G and Rinaldi S 1976 Proc. MMM Intermag cong., Pittsburg p. 214

Figgis B N and Nyholm R S 1958 J. Chem. Soc. Jpn 194190

Henry N F M, Lipson H and Wooster W A 1953 The interpretation of X-ray diffraction photographs (London: Macmillan \& Co.)

Isalgue A, Labarta A, Tejeda J and Obradors X 1986 Appl. Phys. A39 221

Kojima H 1982 in Ferromagnetic materials (Amsterdam: North Holland) Vol. 3

Kubo O, Ido T and Yokoyama H 1982 IEEE Trans. Magn. MAG-18 1122

Kulkarni D K and Prakash C S 1994 Bull. Mater. Sci. 1735

Lotgering F K, Locher P R and Van Stapele R P 1980 J. Phys. Chem. Solids 41481

Rewatkar K G, Prakash C S and Kulkarni D K 1988 Mater. Lett. 28365

Sharrock M P 1989 IEEE Trans. Magn. MAG-25 4374

Smit J and Wijn H P J 1959 in Ferrites (The Netherlands: Philips Technical Library)

Speliotis D E 1987 IEEE Trans. Magn. MAG-23 25

Stepankova H, Kohout J and Simsa Z 1991 Proc. ICM (Amsterdam: North-Holland) Vol. 3, p. 705 